\title{
XLVI. On the lateral vibration of bars supported at two points with one end overhanging
}

\author{
John Morrow M.Sc. D.Eng.
}

To cite this article: John Morrow M.Sc. D.Eng. (1908) XLVI. On the lateral vibration of bars supported at two points with one end overhanging , Philosophical Magazine Series 6, 15:88, 497-499, DOI: $10.1080 / 14786440809463791$

To link to this article: http://dx.doi.org/10.1080/14786440809463791

曲 Published online: 16 Apr 2009.

Submit your article to this journal $\sqsubset \pi$

Џ Article views: 2

Q View related articles $\square$

Citing articles: 1 View citing articles 5 
Lateral Vibration of Bars supported at Two Points. 497 in none of these cases is the p.d. $\mathrm{Hg}$ | electrolyte necessarily zero.

4. It is shown that the Paschen relation immediately fails when the chemical action at the drop-electrode due to atmospheric oxygen becomes appreciable.

5. The Paschen E.M.F. between mercury and a solution of $\mathrm{KCl}$ remains unchanged on the addition to the solution of small quantities of $\mathrm{Na}_{2} \mathrm{~S}$, although the natural p.d. between mercury and the $\mathrm{KCl}$ solution is thereby altered by more than half a volt.

6. A critical percentage of $\mathrm{Na}_{2} \mathrm{~S}$ was found for which the natural p.d. just mentioned altered with extreme rapidity as in the cases studied by Behrend, in which he observed the variation of the E.M.F., $\mathrm{Hg}\left|\mathrm{Hg}_{2}\left(\mathrm{NO}_{3}\right)_{2}\right| \mathrm{Hg}$, produced by the gradual addition of $\mathrm{KCl}$ or $\mathrm{KBr}$ at one electrode. In the present case the change in the p.d. $\mathrm{Hg}$ | electrolyte was deduced directly from the electrocapillary curves.

XLVI. On the Lateral Vibration of Bars supported at Two Points with One End overhanging. By JOHN MoRrow, M.Sc., D.Eng.; Lecturer in Engineering, Armstrong College (University of Durham)*

WHEN a bar is carried on two supports and has one end overhanging by an amount $c$, as shown in the figure,

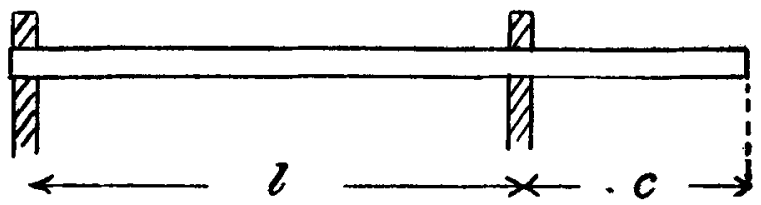

its natural period of vibration is to be determined from the equation

$(\cosh m l \sin m l-\sinh m l \cos m l)(\cosh m c \sin m c-\sinh m c \cos m c)$ in which $-2 \sinh m l \sin m l(1+\cosh m c \cos m c)=0$,

$m=(2 \pi \mathrm{N})^{\frac{1}{2}}(\rho \omega / \mathrm{EI})^{\frac{1}{4}}$;

$\mathrm{E}=$ Young's Modulus for the material ;

$I=$ the moment of inertia of the section about an axis perpendicular to the plane of bending;

$\omega=$ sectional area of bar (assumed uniform);

$\rho=$ density of material ;

$\mathrm{N}=$ frequency of natural vibrations.

* Communicated by the Physical Society : read November 8, 1907. 
498 Lateral Vibration of Bars supported at Two Points.

For given ratios $c / l$ we can obtain values of $m l$ from the above equation. This has been done incidentally by Professor Dunkerley in connexion with his work on the wbirling of shafts *, but the calculations were not sufficiently extended to give very accurate results. By comparison with the table given below, it will be seen that the approximate formula used by Dunkerley cannot be relied on to give more than the first two significant figures.

Having recently required more accurate solutions, I have found it necessary to make a more elaborate calculation, and as the results have been obtained to six figures it appears desirable to place them on record.

If we write $a$ for $c / l$ and $\theta$ for $m l$, and expand each term of the equation in ascending powers of $\theta$ and $a \theta$, we get, as far as the twenty-first powers,

$$
\begin{array}{r}
4 \theta^{2}-\left(\cdot 0 \dot{4}+\cdot \dot{4} a^{3}+\cdot \dot{3} a^{4}\right) \theta^{6}+\left(\cdot 000035273369+\cdot 002116 \dot{4} a^{3}\right. \\
\left.+\cdot 0 \dot{0} 3 \dot{7} a^{4}+\cdot 0 \dot{0} 2116 \dot{4} a^{7}+\cdot 000 \dot{79365} a^{8}\right) \theta^{10}-(\cdot 58730+ \\
106 \cdot 8890 a^{3}+293 \cdot 945 a^{4}+1007 \cdot 811 a^{7}+881 \cdot 834 a^{8}+ \\
\left.106 \cdot 889 a^{11}+26 \cdot 722 a^{12}\right) 10^{-8} \theta^{14}+\left(\cdot 033+13 \cdot 2 a^{3}+49 a^{4}\right. \\
\left.+508 \cdot 8 a^{7}+700 a^{8}+509 a^{11}+297 a^{12}+13 \cdot 2 a^{15}+2 \cdot 4 a^{16}\right) 10^{-11} \theta^{18} \\
=0 .
\end{array}
$$

Assuming values of $a$ and calculating $\theta$ we obtain the numbers tabulated below:-

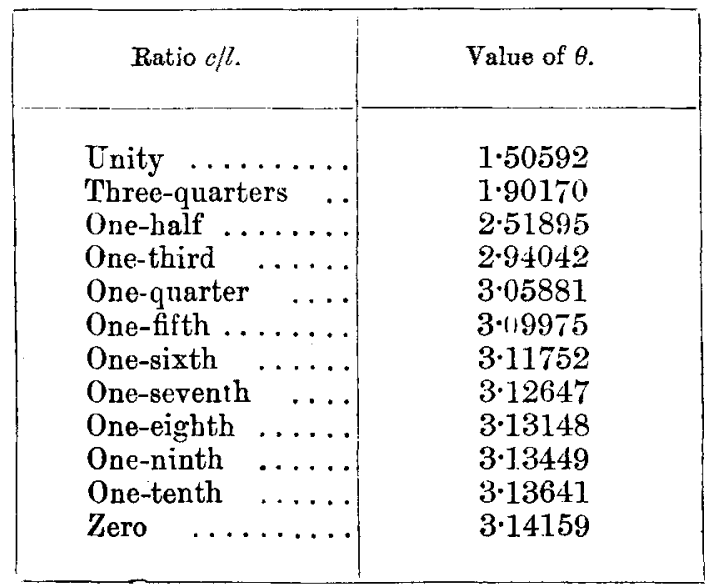

* Phil. Trans. A, 1894, p. 279. 
Dr. Chree has given the following approximate formula for use when $c / l$ is small *:-

$$
m l=\pi\left(1-\frac{1}{6} \pi^{2} c^{3} / l^{3}\right) .
$$

It is stated to be satisfactory so long as $(c / l)^{3} \pi^{3} / 6 \operatorname{coth} \pi$ is small compared with unity. As a matter of fact we find that, when $c / l$ is one-sixth, Chree's formula is correct to within 0.005 per cent., and the error is less than one per cent. even when $c / l$ is one-half.

The number of vibrations per second is given by the formula

September 1907.

$$
\mathrm{N}=\frac{\theta^{2}}{2 \pi} \cdot \sqrt{\frac{\mathrm{EI}}{\rho \omega l^{4}}} .
$$

XLVII. An Experimental Examination of Gibbs's Theory of Surface-Concentration, regarded as the basis of Adsorption, with an Application to the Theory of Dyeing. (From the Muspratt Laboratory of Physical and Electrochemistry, University of Liverpool.) $B y$ W. C. M. LFwIs, M.A.†

\section{Contents.}

I. Object of the investigation; the characteristics of Adsorption Phenomena.

II. Theoretical Discussion; Gibbs's Theory of Surface Concentration ; Milner's Calculations.

III. Experimental Methods and Apparatus; Results.

IV. Application to the Theory of Dyeing.

v. Summary.

\section{Object of the Investigation.}

UN NDER the term "Adsorption" are grouped phenomena which may be regarded as forming an intermediate stage between chemical combination on the one hand, and true absorption or solution on the other. Different types of Adsorption have been studied, but in general a solid substance (e.g. charcoal) has been utilized as the adsorbent body.

The present paper is an account of an experimental attempt at measuring adsorption effects quantitatively and interpreting the values obtained in the light of Gibbs's theory of surfaceconcentration. The treatment is novel in that the adsorption has been measured at a liquid-liquid interface ; for it is only when dealing with liquid interfaces (or surfaces) that it is

* Phil. Mag. [6] vol. vii. p. 517, May 1904.

† Communicated by the Physical Society; read February 28, 1908. 